\title{
Medicolegal Issues in Maxillofacial Surgery
}

\author{
George Paul and Manjunath Rai
}

\subsection{Introduction}

In the modern world, human activity is governed by a set of rules and regulations collectively referred to as law. All professions must follow legal requirements and this is especially important while practising health care, including maxillofacial surgery. Doctors must be aware of their duties, rights and scope of practice within the framework of the laws governing their respective countries or states. This is especially important for maxillofacial surgeons, who straddle the line between medicine and dentistry. This chapter aims to outline the various legal issues that pertain to the maxillofacial surgeon. The laws referenced are mostly India centric, but the general principles are not very different from international laws.

\subsection{What Are the Legal Issues That Must Concern the Maxillofacial Surgeon?}

Since the role of a maxillofacial surgeon acts as a link between the medical and dental professions, the scope of practice has always been controversial. Maxillofacial surgeons have moved from beyond the oral cavity to the head and neck region, and even to distant body parts for procedures such as flap harvesting. All maxillofacial surgeons must be aware of what procedures they are allowed to practice under the law and what they must avoid.

During any procedure, legal documentation is of utmost importance. These include informed consent and filing medico-legal reports. Informed consent is a legal necessity to prove that a patient is willing to undergo a procedure.

G. Paul $(\bowtie)$

Kerala University of Health Sciences, Thrissur, Kerala, India

Dr MGR Medical University, Chennai, Tamil Nadu, India

M. Rai

Department of OMFS, A. J. Institute of Dental Sciences, Mangalore, Karnataka, India
Medico-legal reports must be filed when one treats a case that could potentially become a legal issue. Maxillofacial surgeons may be called upon to testify as expert witnesses in legal cases such as assault and road traffic accidents. They should therefore be aware of procedures required to document evidence in these cases.

Finally, all medical professionals are vulnerable to malpractice suits. The surgeon must be aware of what actions could put them at risks for facing such suits and what procedure must be followed if one ever faces a malpractice litigation.

\subsection{Scope of Practice of Maxillofacial Surgery as per the Indian Law}

\subsubsection{Historical Perspective}

Oral and Maxillofacial Surgery has a unique place in the health care systems around the world. It is a stand-alone speciality in modern medicine that has its provenance in dentistry. However, when one realizes that modern medical systems are barely more than a century old, it is not long ago that the treatments of dental and oral diseases were a part of an integral system that encompassed holistic health care.

Dentistry as a separate autonomous specialty is an accident and an aberration in the history of modern medicine. In fact, the first dentists were medical doctors or surgeons like Pierre Fauchard in France who had a special interest in treating dental and oral conditions [1] and John Hunter [2] in England.

In the late nineteenth and early part of the twentieth centuries, dental schools and curriculums were established as courses separate from medical courses and the bifurcation became an established practice in different countries in almost all continents [3, 4].

It is through this prism that we need to view the speciality of OMFS and its future as a complex and distinct part of health care. In fact, training to become a maxillofacial 
surgeon through the route of dental surgery is unique when compared to other distinct regional specialties, which emerge as a post-medical qualification, e.g. ophthalmology, otolaryngology, or gastroenterology.

Realizing the need for adequate training in surgery, substantial additions were made to the dental and oral and maxillofacial surgery curricula by including several basic medical sciences and clinical medical subjects in the undergraduate and post-graduate level, to help meet the medical training requirements of a surgeon.

The impetus for the evolution of OMFS was provided by the two World Wars of the twentieth century and other armed conflicts, where dental and oral surgeons were found to be invaluable in the treatment of facial bone fractures. Thus, Oral and Maxillofacial Surgery was born as a speciality of dentistry and went on to encompass a wide range of surgical work, including pathologies of the mouth and jaws, TMJ surgeries, surgical corrections of dento-facial deformities and cosmetic surgery of the face.

In many countries, including those in Europe, this resulted in the concept of dual degrees (medical as well as dental degrees) to better address surgery in a complicated region of the body where one needed a clear understanding of surgical principles as well as sound dental concepts. Duality is often mistaken for an additional medical degree. In fact, duality includes the need for a dental degree for those with a medical background. In countries like USA, India and several Asian countries, oral and maxillofacial surgery continues to be a surgical speciality of dentistry, although some surgeons chose to do medicine as additional qualification to further their interests and knowledge [5]. Similarly, dentistry was offered as an additional degree for those with medical qualifications only. Dentistry was however an essential pre-qualification to become a maxillofacial surgeon. It must be remembered that $90 \%$ of the world population is still serviced by OMFS with a single dental qualification re-enforced by rigorous surgical training as part of their post-graduate curriculum. This includes the USA, Canada, Latin America and the Caribbean, Africa, China, Russia, Central Asia, South Asia, Middle East Asia, South West Asia, Japan, and Far East Asia [6-12]. Starting in the 1970s, several countries also offered integrated 6-7 year residencies leading to OMFS that provide an additional Medical or Dental degree depending on their original background.

The curriculum for Oral and Maxillofacial Surgery in India and several other countries has been suitably modified for patient safety and competence. In India, the speciality of OMFS is regulated by the Dentist Act of 1948 as more than $90 \%$ of OMFS are dental-qualified surgical specialists [13]. OMFS has been included as a recognized speciality with distinct privileges in the medical health care system and has been included in significant legislations at the national and state levels, including the Clinical Establishment Act of 2012.

\subsubsection{Current Legal Privileges}

Oral and Maxillofacial Surgery is a recognized department in most multi-specialty hospitals and they are given privileges such as admissions and autonomous departments within the surgical or dental services.

The Dentist Act has defined Oral and Maxillofacial Surgery as a surgical branch of dentistry dealing with diseases affecting the mouth, jaws, and face. The updated curriculum of OMFS is a focused training in surgical management of diseases, injuries and deformities of the face and gnathic system. Training includes interdisciplinary rotation with allied surgical specialities and standard competence in dealing with complex surgical situations in the mouth, jaws and face.

In an increasingly competitive surgical arena, different surgical specialities compete for ownership of procedures based on their diverse backgrounds. It is therefore expected that OMFS, as an emerging surgical specialty, is sometimes in conflict with other specialities.

The legal competence to perform procedures is dictated by the qualification and training received as part of the curriculum set up by the respective statutory bodies through due process of law.

The legal remit and privileges of OMFS in India are based on the training received as part of the curriculum of the master's degree in Oral and Maxillofacial Surgery as outlined by the Dental Council of India in its regulation issued from time to time. The current syllabus, curriculum and training equip the specialist to deal with a wide range of surgical procedures in the face, jaws, oral cavity and teeth. This includes comprehensive management of defects or deformities of dento-facial region caused by congenital anomalies, injuries or surgical ablation. However increased competence, like in any other surgical speciality, is achieved through experience and continuous training in the form of fellowships and structured courses.

Oral and Maxillofacial Surgery falls into a grey area, overlapped by several other surgical specialities. However, competence is defined by the scope offered by legally approved training within the framework set out by the statutory bodies in the respective countries. In India, OMFS is an advanced surgical specialty of dentistry and its remit is regulated by the Dental Council of India.

\subsection{Legal Requirements to Be Followed When Dealing With a Patient}

\subsubsection{Informed Consent}

Consent to medical treatment as an ethical and moral principle is probably as old as medical science. It is inconceivable 
that a medical practitioner at any point in history would have treated or operated on a patient without his or her permission. However, consent to treat as a legally binding entity is of recent origin. Today, it is validated by multiple principles drawn from social and behavioural sciences, moral philosophy, human rights, ethics and laws of a particular country. One of the main guiding principles of Informed consent involves the rights of patients to make clear assertions of what can or cannot be done to their bodies based on unbiased and full disclosure of the benefits and risks that will ensue from treatment. While most diagnostic treatment procedures are today performed only with a clear informed consent, there are some which attract particular attention in the matter of informed consent, e.g., HIV testing and high-dose radiation in vulnerable patients.

\subsubsection{Definition and Principles of Informed Consent}

Farlex's free online dictionary [14] has a simple definition of Informed Consent. It is "Consent by a patient to a surgical or medical procedure or participation in a clinical study after achieving an understanding of the relevant medical facts and the risks involved." A more descriptive definition is sometimes employed to capture the nuances of informed consent. It may thus be defined as "Consent given by a patient after understanding his/her condition, procedure, risks and alternatives based on unbiased information by the medical professional in a language and manner which is unambiguous, lucid."

\subsubsection{History and Theory of Informed Consent [15]}

The key historical signposts in the evolution of the Informed Consent as a valid legal document can be traced to cases from the US judicial system, though the basic principles find their roots in English Common law.

- While consent has been a well-known moral requirement before treatment, it gained legal sanctity only in 1914 with the case of Schloendorf Vs Society of New York Hospitals. It set the tone for a legally acceptable premise of self-determination [15]. Justice Benjamin Cardoza summarized the basic philosophy in his judgment thus "Every human being of adult years and sound mind has a right to determine what shall be done with his own body and a surgeon who performs an operation without his patients consent commits an assault for which he is liable."

- However, it was with a series of case in the 1960s and 1970s that self-determination came to be legally binding as a legal principle and more importantly the importance of full divulgence by the doctor based on which a consent can be made became a dictum. Important cases include the Salgo Vs Le Land Stanford Jr Case (1972) and the
Canterbury Vs Spence Case (1972) [16]. Thereafter, not obtaining informed consent became legal violation, equivalent to assault or "battery".

- With the advent of new technology and emergence of new diseases like HIV, Informed Consent documents are constantly being upgraded to include new medical procedures.

- Informed Consent Document (ICD) in research was largely evolved due to the World War II atrocities in Nazi Concentration camps. ICDs in research have been formulated and reviewed by the Nuremburg conference and the Helsinki declaration. They are closely monitored for content by organizations such as the WHO, FDA, and the ICMR in India.

\subsubsection{Types of Informed Consent [17]}

Informed consent may be of two types:

1. Implied and

2. Oral or written Consent

- Implied Consent: It is given by the behaviour of the patient, such as entering the clinic and opening the mouth to be examined, etc.

- Oral Consent: It is acceptable for inconsequential procedures such as examination, taking of impressions, or even routine low-exposure X Rays, etc.

- Written Consent: While oral consent is an acceptable consent, it can often be challenged and the consent cannot often be proved or validated. It is therefore more binding to give a written informed consent.

\subsubsection{Informed Consent in Oral and Maxillofacial Surgery}

Informed Consent for orthognathic surgery is particularly important because of the nature of the procedure. It is an elective procedure and the patient often seeks treatment for enhancement of aesthetics and function. The expectations are high and therefore the scope for disillusionment as well.

Orthognathic surgery is a highly skilled procedure in a complex anatomical area. Treatment often involves multiple specialists, including orthodontists, anaesthetists, general dentists, and other surgical specialists like neurosurgeons, otolaryngologists, or plastic surgeons. In addition to results falling below expectations, which are largely subjective, patients may also have morbidity in the form of neurological deficit, infections, occlusal discrepancy, TMJ problems, and in rare situations excessive exsanguinations and even death.

Maxillofacial Surgery is a unique speciality of dentistry and medicine and involves complex procedures and outcomes. Some of the procedures are cosmetic whereas others are ablative. Being a surgical procedure involving the mouth, jaws and face, there are several issues of deformity and disability. 
The informed consent should include the following (Box 44.1):

Box 44.1. Components of Informed consent for surgery

1. the purpose of the proposed procedure;

2. a summary of the surgical approach;

3. expected benefits and limitations;

4. a description of postoperative recovery; possible complications and known side effects, including those that are rare.

5. risks associated with the procedure and/or medications should include alternatives, including the option of no treatment or surgery at all.

Irrespective of whether the surgery is a minor dento-alveolar extraction or major reconstructive procedure, it may be cautious to take an informed Consent, which includes chance of injury or consequences that have disutility for the patient. While operating as a team there are decisions that can be taken jointly by the other members in the treatment process, e.g., Neurosurgeons or orthodontists. For instance, in orthognathic surgery, the Informed Consent Document may have several distinct parts. Gasparini G, Boniello R et al. suggest a threepart informed consent to include pre-op orthodontics, orthognathic surgery and post-op orthodontic treatment [17].

The informed Consent document may need to include the following principles and the surgeon and his team can make appropriate changes to accommodate them. These have been enunciated by Lord Scarman in the case of Sidaway v Board of Governors of Bethlehem Royal Hospital [18].

1. The individual should be of adult years (18 years in India) and sound mind and should have the legal mental capacity to choose what happens to his body.

2. It should offer a choice that entails an opportunity to evaluate knowledgeably the options available and the risks attendant on each (including no surgery option)

3. The doctor should therefore disclose all material risks. The material risks are determined by the "prudent patient test," which determines what a "reasonable" patient in a position of a plaintiff (complainant) would attach significance to, in coming to a decision on the treatment given.

In addition to this, in the Indian context:

4. All informed consent must be in a language understood by the patient (vernacular languages like Tamil, Malayalam, Bhojpuri, Kannada, etc.)

5. In case of illiterates, the informed consent must be read to them in the presence of an independent witness who must sign on the space provided.

6. In children below 18, a parent or guardian can sign on behalf of the child.
Recent concerns have suggested that informed consent should also cover diagnostic tests. It is a common practice in some countries, including India, to do a routine HIV testing. These can be undertaken only with an informed consent, including pretesting counselling. Many countries also insist on informed consent for multiple high-dose radiation, especially with the use of CT scan.

**A standard Informed Consent form is attached and can be used as a template. Any change depending on local conditions can be added (addendum).

\subsubsection{Informed Consent and Negligence in Oral and Maxillofacial Surgery}

Informed consent regulations today are largely governed by the principles of medical negligence rather than the tort of battery as in the early days. Any injury, even expected, may be considered a negligent act if there is no informed consent, e.g., paresthesia following Impactions or BSSO. The situation can be defended if the patient was informed and consent obtained. The civil liability for the same will be similar to the liability for medical negligence.

Similarly, Informed consent does not absolve the surgeon from liability for negligence, if it is proved that it could have been avoided if the surgeon had exercised reasonable care.

In short, liability for negligence can be mitigated by an informed consent, but informed consent cannot totally absolve a surgeon for an obvious negligent act.

\section{Defence for non-information}

Sometimes, the surgeon may encounter a non-reported or rarely reported complication despite reasonable care. In these situations, they can take defence in the principle of "Act of God!!" These are complications or sequels that may not have been anticipated by a reasonable surgeon.

\section{Exceptions for the use of Informed consent}

- Life-threatening situations, e.g., Carotid Ligation, Tracheostomy, etc.

- Incapacity of patient by virtue of age or mental status (It is taken from the guardian/parent).

\subsubsection{Informed Consent for Clinical Trials and New Techniques}

Informed consent has to be obtained if the patient undergoing the surgery is the subject of a new device, implant, or technique which is not a standard one. In India, devices are not covered by the DCGI (Drug Controller General of India). New techniques on an experimental basis, particularly in teaching institutions, must be communicated to the patient and should be cleared by an Institutional Review Board (IRB) or 
Independent Ethics Committee (IEC). The ICD requirements for research are clearly enunciated in India by the ICMR.

In conclusion, Informed Consent Documentation is an important and critical part of all treatment plans and often includes invasive or potentially harmful investigations. A proper informed consent that is realistic and involves full disclosure, if the patient is exposed to a chance of injury for which he has no utility, is a necessary part of all treatment protocols. Informed consent documents respect the right of patients to take a decision on how their body is treated based on all available information. It is a moral, ethical and legal obligation to obtain a consent based on credible information. It also provides a safety net for the surgeon when unexpected adverse complications occur.

\subsubsection{Dentist/Maxillofacial Surgeons as Expert Witnesses}

Dentists and maxillofacial Surgeons are often called upon to give evidence in case of civil or criminal cases. When surgeons are called upon to give evidence as part of forensic evidence, they need to have a grasp of the subject. Forensic medicine and odontology have been used in many sensational cases in India, the Rajiv Gandhi assassination being one of the better-known ones.

Surgeons are often called upon in other more common situations as well.

1. Evaluation of disability after dental or maxillofacial injuries.

2. For opinions regarding the procedures adopted by other doctors/dentists in cases of alleged negligence.

Expert witnesses are issued summons as discussed earlier in the chapter. The surgeon is obliged to present himself before the court at the appointed time. He may be questioned by the lawyers of the prosecution, defence or the insurance company, as to the nature of injury and the quantum of disability. The surgeon is to clearly state his/her opinion without ambiguity and should remain non-committal about subjects that they are not sure about. If the surgeon has issued a wound certificate, the copy of the same will be given to him for reference at the time of testifying. The witness is to merely state the facts. They are not expected to involve themselves with the law on the subject, e.g., Loss of teeth, fracture of jaw, etc. They may answer truthfully to any other question pertaining to the same.

Today, there are only a few quantified disability criteria for dental and maxillofacial impairment in India. They include "The Manual for Permanent Disability" brought out by the CGHS, WHO, and AIIMS in 1981. A compendium of suggested dental and maxillofacial deformities/disabilities has been suggested by Paul $\mathrm{G}$ and Thomas $\mathrm{S}$ in the published book Medical Law for the Dental Surgeon [19]. It has been extensively used in courts of law. If unsure, the surgeon may state if the injury is grievous or not. He may also elaborate on the actual disability that the defect might cause.

Examples of grievous injuries are:

1. Fractures and loss of teeth.

2. Fractures of jaw.

3. Extensive soft-tissue injuries and scarring

4. Neurosensory or motor disturbances

5. Restricted function, e.g. limited mouth opening

\section{Duties of Witness}

Failure to appear in court without valid reasons after warrant has been issued can invite contempt of court.

Exaggeration or false statements given under oath are not only unethical, but can invite punishment under sec.181, sec. 193.

\subsection{Medical Negligence in Maxillofacial Surgery}

\subsubsection{What Is Negligence?}

Negligence is usually a civil wrong or tort. It is the single most important issue in medical law pertaining to litigation for damages.

By definition, negligent torts (civil wrongs) are not deliberate but rather a failure to act as a reasonable person should in the conduct of duties to someone whom he or she owes a duty to.

The liability for negligence can however also be criminal or statutory.

\section{Negligence as Tort (Civil liability)}

It has several formal definitions, but a convenient one by Alderson explains it rather lucidly as "the omission to do something which a reasonable man, guided upon those considerations which ordinarily regulate the conduct of human affairs, would do, or doing something which a prudent and reasonable man would not do."

For an act to be considered negligent, the following aspects must be present, in regard to a surgeon (Box 44.2).

Box 44.2. Features of a Negligent act

1. That the surgeon owed a certain standard of care.

2. That the doctor/surgeon did not maintain that standard.

3. That there was an injury resulting from the lack of care.

4. There should be a proximate or causal relationship between the negligent act and the resultant injury. 


\section{Exceptions to negligence}

Normally, carelessness is neither culpable nor a ground for legal liability, as there is no wrongful intention. However, in medical negligence, the outcomes have serious implications on the patient in particular and the public in general. The consequences of negligence by a surgeon who owes a duty of care are enormous and the law has imposed a duty of carefulness on the doctor or health worker in the interest of safe practices. However, there are several situations, which do not conform to the strict definition of negligence. In India, several judicial orders have placed many actions by doctors outside the ambit of negligence.

A review of Consumer cases (Under the Consumer Protection Act) shows that some of the situations mentioned here do not come under medical negligence.

- Not providing an ambulance, due to non-availability of the service does not constitute a negligent act.

- Any adverse outcome for a procedure done in good faith, in an emergency, beyond the call of duty, is not considered a negligent act. It is also called the Good Samaritan Act in some countries.

- Mere patient dissatisfaction with progress of treatment or desired relief cannot be construed as negligence.

- Non-availability of beds in an ICU is not negligence.

- Giving precedence of one patient over the other based on clinical risks or emergencies is not negligence.

- A fee, being perceived as exorbitant by the patient, is not negligence.

- Non-availability of a doctor outside his or her working hours may not constitute negligence.

\subsubsection{Duty of Care}

\section{Minimum standard of care}

The degree of carelessness for a particular profession depends on the risk that it poses to the person who is exposed to it.

Professional standard of care is therefore that standard of care or skill that is laid down by a body of professionals on behalf of the medical profession and which a surgeon or physician is expected to bring to his duty.

If skill and knowledge fall below this established standard, it will be considered to be negligent. A body of professionals can establish this standard by publication in books, reports of scientific studies, or by protocols established by them, e.g., text books, journals and protocols created by professional associations. Today, evidence-based science is the hallmark of best practices and is defined by the quality of evidence established through Randomized Clinical Trials (RCT) and meta-analysis of peer-reviewed publications.

When there is a difference of opinion on technical matters, an alternate method recognized by another body of pro- fessionals will be acceptable as a valid procedure and will not be considered as negligence. This is ascertained by the application of Bolam's law [20], which recognizes reasonable difference of opinion based on credible evidence or experience among peer professional groups.

The Bolitho test uses a different legal parameter and has undermined the usual dependence on the Bolam test. The Bolitho test goes beyond dependence on just two opinions and looks at credible scientific evidence as more important than mere difference of opinions.

In this context, it is important to discuss the semantics of customary and acceptable.

A professional cannot adopt a procedure merely because it is customary. Customary standards have been looked at critically because it does not provide incentive to adopt better practices. Because a particular procedure has been done for many years does not make it an acceptable practice. An acceptable practice, on the other hand, is not only time tested but also scientifically sound. An acceptable practice is usually the product of evidencebased science as opposed to customary practice, which is either anecdotal or proven to be inadequate or irrelevant by scientific scrutiny.

An often-quoted legal principle is that "The skill, diligence, knowledge, means and methods are not those that are ordinarily or generally or customarily exercised or employed, but those that are reasonably exercised or applied, negligence cannot be excused on the ground that others practice the same kind of negligence."

It may therefore be said that a "health worker is under a duty to use that degree of skill which is expected of a reasonable competent practitioner in the same class to which he belongs, acting in the same or similar circumstances." The Supreme Court has defined this duty in the case of Indian Medical Association Vs V.P. Shanta [21] as "In general a professional man owes to his client a duty in tort (civil wrong) as well as in contract to exercise reasonable care in giving advice or performing services."

Importantly, the court held that this standard should be outlined by the medical profession and it is not the duty of the "lay courts" to decide on what constitutes "standard" care. Negligence, in these situations, may be dependent on the locality, availability of facilities, specialization of the doctor, proximity to specialists and advanced technology. However, it is important to remember the dictum "no man is bound in law to be a good surgeon, but all men are bound not to act as a surgeon until he is good and capable as such."

The foregoing dictum indicates that a physician or surgeon should not venture to do a procedure unless he is trained and competent in performing it. Merely admitting that he had inadequate experience is no legal remedy. In other words, it is not legally wrong to be ignorant, but it is legally wrong to act in ignorance. 


\subsubsection{The Test of Negligence}

\section{The Bolam Test}

This is a classical test widely used in the United Kingdom. The Bolam test is an acceptable test used by the National Health Service of the U.K. when a situation of negligence presents itself as observed in the landmark case of Bolam Vs Friern Hospital managing committee. (1957) 2 AIIER 118.

The Bolam test establishes that standard procedures be the basis of treatment. Importantly, it provides for alternate management protocols. If there is more than one school of thought, both alternates will be acceptable as a standard.

\section{Bolitho Test}

In a minority judgment comments in Bolitho, it was emphasized that the word "responsible" in the traditional formulation of the Bolam test meant that responsible practice is that which withstands the scrutiny of "logical analysis" from a judicial perspective. Today, courts are increasingly scrutinizing risk analysis from a patient view point, which undermines the traditional view point of only the care giver.

\section{Negligence-Carelessness vs. Recklessness}

While both words have almost the same meaning, there is a small difference. A careless person may not think of the eventuality while being careless. On the other hand, the reckless person is fully cognizant of the injury that his act may cause, but still takes the risk of possible injury. The former is passive, whereas the latter is an active act. Both acts are however are not intentional and is therefore often used to describe negligence.

\section{Standards of Care in Hospitals}

Legal standards applicable to hospitals are somewhat similar to those required of doctors or other health workers.

The hospitals are bound to maintain standards in two ways.

1. The facilities of a hospital should be that of a reasonable hospital engaging in similar type of health care.

2. The Hospitals should maintain standards laid down by statutory provisions (if available). In India, there are now basic standards for all medical establishments, which are defined by a legislated statute called the Clinical Establishment Act. It provides for the basic requirements of different categories of hospitals and the role of personnel in providing standard care.

In addition, the hospitals may be answerable for the negligence of their doctors, nurses and other health workers through what is called vicarious liability.

\subsubsection{Contributory Negligence}

In some situations, negligence arises fully or in part due to the patients or the complainant's fault. As the patient, wholly or partly, contributes to the negligent act, it is called contributory negligence.

The standard to be adopted to assess contributory negligence is somewhat similar to the standard adopted for the doctor. It may be said that 'contributory negligence is when a competent adult (patient) may be negligent by contribution when his conduct falls short of the degree of care that society expects a reasonable person to do or not to do for his own safety'. This would obviously preclude children and mentally incapacitated adult.

Examples

1. When a patient refuses to take a prescribed medication resulting in postoperative infection.

2. A patient who removes inter-maxillary wiring on his own resulting in non-union.

\subsubsection{Remedy for Negligence Under the Indian Legal Systems}

Negligence can be

1. Tortious (Civil wrong)

2. Contractual (Breach of contract)

3. Criminal

4. Vicarious (Liability passed on to hospital or employer)

Negligence can be remedied depending on what legal provision the complainant wishes to seek remedy.

The punishment under the law of Tort (Tortious liability) is unliquidated damages, i.e. whatever damages the judge wishes to award depending on injury, circumstances and other considerations like age, earning potential, profession, etc.

If an implied agreement was made between doctor and patient, then the remedy would be as specified in the contract. The judge may order a specific performance to do or not do something he has agreed to. However, guarantees for treatment are against ethical guidelines for treatment and it is not applicable in medical law.

If the complainant seeks punitive action against the doctor, he may file a criminal case under the relevant statutes. The Indian Penal Code for example, has provisions to punish doctors for death or disability. The remedy under criminal law is always in the form of a punishment (Penal). It may involve imprisonment or fine or both. Rarely, the court can order compensation or specific performance as well. Criminal law sees negligence as a crime against the state and not just against the plaintiff. 
Doctors may also be liable under professional statutory laws governing the practice of the profession. In India, statutory bodies such as the Medical Council of India or the Dental Council of India can prescribe punitive action in accordance with laid down laws. The laws can be initiated only against persons registered under the particular statutory body. The Medical Council of India, for instance, cannot take action against a dental-qualified maxillofacial surgeon.

In some instances, a doctor may not have to answer for his negligence directly. The hospital or establishment employing him may have to answer to the allegation to negligence. This is called vicarious liability and is usually relevant to salaried employees who work for a contract of services and not a contract for services.

However, in practice, for the sake of regularity, it may be said that all permanently or part-time employed doctors are only vicariously liable. However, if the patient is admitted by a doctor in his personal capacity, then the doctor will be personally liable.

\section{Contractual nature of liability}

In a doctor patient relationship, an implied contract is established when a doctor accepts a patient for treatment. A breach of any aspect of this implied contract may amount to negligence when the doctor is under duty to

1. Treat with care

2. Continue to treat and not terminate until patient is cured or the patient discontinues treatment.

This may be considered the contractual nature of medical liability. However, Medical ethics does not provide for a written contract, which can be violated as in the case of a commercial transaction. So any liability based on breach of an implied contract will essentially lie within the realm of tortious liability.

Written contracts with promise to cure, failing which a refund is assured is against the ethics of medical or dental practice. It is this author's view that such contracts can be technically void, considering the ethical and legal issues involved.

Tortious Liability is usually dealt with in Civil Courts. In India, medical negligence comes within the ambit of the Consumer Protection Laws established to provide speedy relief to plaintiffs seeking redressals for goods and services that fall short of standards. The Consumer Protection Act defines medical care as contract for services, which makes doctors and hospitals liable under the Consumer Protection Act of 1986. The Consumer Courts are quasi-judicial legal redressal forums established for speedy justice. They are tiered under the District, State and National Forums depending on the place of the cause of action and the pecuniary jurisdiction (amount claimed as damages).

\section{Criminal Liability}

This liability normally lies with an identifiable individual or groups of individuals. However, recent trends indicate that Hospitals also may be held vicariously liable just as in civil liabilities.

Criminal liability is penal and involves punishment in the form of imprisonment or fine or both. Criminal negligence is considered to be a crime against society and not just the aggrieved party and is in violation of penal codes of countries. In India, it is a violation of various sections of the Indian Penal Code 1868 (amended several times).

The important offences inviting criminal liability with regard to negligence are:

1. Sec 304 A (IPC)—negligent homicide. A rash or negligent act resulting in Death, e.g. death on the dental chair or hospital or operating room.

2. Sec 336 (IPC) An act endangering the life of a person (even if there is no injury), e.g. conscious sedation without essential monitors or oxygen, even if no harm is caused.

3. Sec (337) (IPC) A rash or negligent act causing a simple injury, e.g. mild reversible thermal burns caused by bonesectioning equipment.

4. Sec (338) (IPC) A rash or negligent act resulting in grievous injury, e.g. fracture of jaw during extraction due to excessive or improper force or avascular necrosis following osteotomy.

While these are the common sections under which a doctor may be liable, other sections also apply. Any offence against the human body (Sec 299 to Sec 377) or offences against property (Sec 378-462) can be used against doctors, e.g. abetting suicide, causing miscarriage sec 312-316 (subject to exemption from the Medical Termination of pregnancy Act 1971), etc.

Sections $78,80,81,87,88$ are directly or indirectly relevant to the medical practitioner. Some can be used in defence of the doctor accused of negligence. Section 88 for instance is an act done in good faith not intended to cause death. It is a good defence in emergency care. Sections 86 and 87 IPC are in respect to harm or death caused by an act not intended to cause harm or death and is done with consent in the best interest of patients. Section 499 deals with defamation. It can be used by doctors to counter malicious charges by patients intending to spoil the good name of the doctor by frivolous or vexatious charges. It can also be used by patients as a criminal violation of confidentiality statutes. For example, revealing HIV status when the patient is not likely to be a public health hazard. 
It is important to understand some terms in connection with criminal liability (Box 44.3).

\section{Box 44.3. Terms related to criminal liability}

- Cognizable Offence: A police officer can arrest without a judicial warrant based on his investigation.

- Non-Cognizable: An arrest can only be made by a judicial warrant.

- Bailable: the arresting officer can provide bail. Bail is a matter of right and has to be given unless the officer apprehends that the accused may abscond or tamper with evidence.

- Non-Bailable: Bail can be secured only from a magistrate. Heinous and violent crimes fall in this category, e.g., if there is a significant risk that the offender may commit further crimes, abscond or tamper with evidence.

- Compoundable: A crime in which a compromise between the suspected offender and the victim or his attendant can be worked out it is said to be compoundable

- Non-Compoundable: If the crime is against society and is of a serious nature, no compromise can be made between the accused and the victim. These cases are said to be non-compoundable.

- Sec $304 A$ is cognizable, bailable and non-compoundable. It can be punished with imprisonment of either description for a term of 2 years or fine or both.

- Sec 337 and 338 are cognizable, bailable and compoundable. Sec 337 may attract an imprisonment up to 3 months and a fine up to Rs $250 /$ or both. Sec 338 can involve imprisonment up to 2 years and a fine up to Rs $1000 /$ or both.

It is important for the surgeon to be aware of these liabilities. It is also important for him to understand his rights. For example, bail is a matter of right in the foregoing situations and it is to be given by the police officer attempting to arrest a medical professional. Bail is granted on the surety given by the doctor or a colleague. A doctor can give surety on his own reputation. The burden of providing reasons for refusing bail rests on the police officer and he will have to give convincing reasons for not granting bail.

\section{Representations to amend Criminal procedures for arresting Doctors}

Doctors cannot be arrested arbitrarily.

In a landmark case referred to as the Jacob Mathew Case (2002), the Supreme Court of India has prevented arbitrary arrest and detention of doctors even in case of death or serious disability, as a part of treatment. Criminal liability and arrest can only be made on the basis of a credible Medical Board opinion duly constituted or recognized by the Government.

\section{Statutory Liability}

A doctor or nursing home is liable if there is any infringement of Statutes (rules). They then become accountable to a statutory body. The liability depends on the kind of infringement and the provisions in the statute to deal with it. There are many statutes dealing with practice of Doctors and Dentists, as well as Hospitals. Recently, the newly legislated Clinical Establishment Act provides guidelines for the whole of India.

Doctors and dentists may also be liable to other statutory laws such as The Pollution Control Board and the Drugs and Cosmetics Act, etc.

\subsubsection{Legal Procedure and Evidentiary Requirements}

(With special reference to medical/dental Negligence)

Legal Procedure (Procedural Law) Relevant to Medical/ Dental Negligence.

It is important for the doctor/dentist to know the legal procedure involved in medical negligence. The legal procedure is slightly different for civil negligence, criminal negligence, and negligence under the Consumer Protection Act.

To understand legal procedures, one must be familiar with some of the procedural laws. They are,

1. Civil Procedure Code.

2. Criminal Procedure Code

3. The Indian Evidence Act

4. The Limitation Act

5. The Court fees Act

6. Procedure under CPA.

\section{The Evidence Act}

It is a very important procedural law. There are three concepts in Evidentiary Law.

1. Facts

2. Facts in Issue

3. Relevant Facts.

The facts are the material evidence.

The "facts in issue" are those that have to be explicitly proved. The facts in issue are proved by bringing into evidence the relevant facts. Sections 6-55 deal with these relevant facts.

There are also other rules in Evidence Law.

- Who needs to bring in Evidence? 
The person who has to legally bring in evidence to prove or disprove a fact is said to have the "burden of proof"', When one has the burden of proof he has:

1. The burden of establishing a case

2. The burden of introducing evidence.

The general rule (with some exception) is that the onus of proving any particular fact lies with the party who alleges it and not with the party who denies it. In other words, the onus of proof lies with the complainant and not with the defendant.

Negligence can be proved by

1. Direct Evidence

2. Circumstantial Evidence

3. Res ipsa loquitor (The matter speaks for itself)

- Another aspect of evidentiary law is standard of proof.

The standard of proof in civil cases can be based on probability and circumstantial evidence. However in a criminal case, the standard of proof is more stringent and should be beyond reasonable doubt as sanction in criminal law is more severe and penal in nature.

- The limitation act (1963)

It is the statute dealing with the time limit for various suits, appeals, bail application and other legal actions.

\section{- Cause of Action:}

This refers to the incident, which has necessitated a legal process. Limitation period begins as soon as the cause of action takes place. The period of time varies according to the suit and it is given in the schedule of limitations.

\section{Appeals/Application for leave of appeals}

For appeals, the day of judgment marks the beginning of limitation period after giving time for obtaining the copy of decree (Judgment Order). This will not include 'writs' as the limitation Act does not apply to them.

If a suit or appeal is made after the statutory limitation period, the court may reject the petition on grounds of being barred by limitation. The court may however accept a petition even if it is barred by limitation, if it is satisfied that the delay was unavoidable. However, in criminal cases, the Act does not provide a period of limitation. Criminal proceedings can be instituted at any time after the offence has been committed. However, as per the guidelines given in Section 468 of $\mathrm{CrPC}$, the limitation periods run thus:

(a) 6 months for offences punishable with fine only.

(b) 1 year for offences punishable with imprisonment up to 1 year.

(c) 3 years for offences punishable with imprisonment up to 3 years (not less than 1 year).

If the limitation period ends on a day when the court is closed, then the next working day is included as the limitation period. It may therefore be said that a suit should be filed as soon as the cause of action occurs.

\section{Court Fees Act (Varies from State to State)}

Any party who wishes to approach a court with litigation has to pay a court fees with some exceptions like the Consumer Court. Each state may have a different court fee structure. In a suit for money, the fee is usually computed based on the amount claimed by the plaintiff. Court fees are paid in the form of Stamps, which may be adhesive or impressed or both.

\subsection{Conclusion}

This chapter is unique as most textbooks do not address issues pertaining to law and ethics in practice.

The maxillofacial surgeon is often confronted with questions on their remit and scope of work as it overlaps with several other specialties and is constantly in conflict with issues of qualification and areas of competence. The sections on these issues will throw light on their practice privileges in addition to dealing with litigation for medical negligence, which has become all pervasive.

Disclosure Authors have no financial conflicts to disclose.

\section{Annexures}

\section{A.1 AOMSI-Informed Consent Forms for All Procedures https://www.aomsi.com/ WebPages/downloads.aspx}


1. Health questionnaire

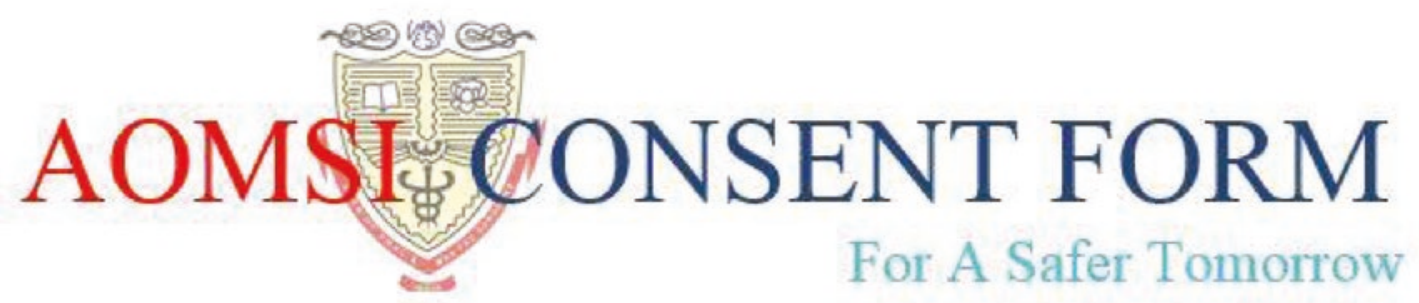

ORAL \&MAXILLOFACIAL SURGERY

HEALTH QUESTIONNAIRE

Patient's Name

Age/Sex

Date

Please initial on each page after reading. If you have any questions, please ask your doctor BEFORE initialing.

Have you had any of the following Problems? Please tick YES or NO

GENERAL PROBLEMS:

- Cold, cough --------------'Yes $\backslash$ No

- Fever. ----------------------------------------Yes $\backslash$ No

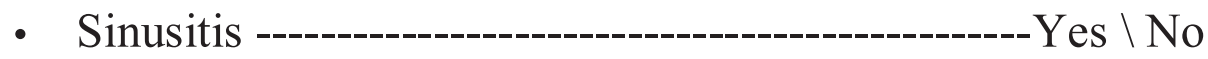

(If Yes, when was the last episode

RESPIRATORY PROBLEMS:

- Nasal obstruction

- Asthma

- Shortness of breath

- Tuberculosis ( TB).

- Bronchitis.

- Emphysema

- Lung diseases. 
HEART PROBLEMS:

- High blood pressure

- Chest pain

Signature

- Heart attack

- Heart murmur

- Pacemakers

- Rheumatic fever

- Irregular heart beat

- Infective endocarditis .

- Angioplasty / Angiogram.

- Bypass surgery.

(If Yes, mention the details of medication, Procedure date \& last visit to the Physician

CNS PROBLEMS:

- Seizures/ epilepsy

- Stroke

- Paralysis

- Brain tumor

- Muscle weakness

- Neuralgia

(If Yes, mention the details of medication, Procedure date \& last visit to the Physician

GIT PROBLEMS:

- Acidity

- Peptic ulcers

- Gall bladder stones

- Colitis

- Appendicitis 
- Piles

- Fistula and fissure

Signature

(If Yes, mention the details of medication, Procedure date $\&$ last visit to the Physician )

LIVER AND KIDNEY PROBLEMS:

- Cirrhosis

- Liver failure

- Kidney stones

- Kidney failure

- Prostate obstruction

- Urinary obstruction

(If Yes, mention the details of medication, Procedure date $\&$ last visit to the Physician

BLEEDING PROBLEMS:

- Anemia

- Clotting and bleeding time

- Platelet count

- Haemophilia

(If Yes, mention the details of medication, Procedure date \& last visit to the Physician

ENDOCRINE PROBLEMS:

- Diabetes 
- Thyroid

- Steroids.

(If Yes, mention the details of medication, Procedure date \& last visit to the Physician

PSYCHAITRIC PROBLEMS \& COUNCILLING

(If Yes, mention the details of medication, Procedure date \& last visit to the Physician

ARTHRITIS:

(If Yes, mention the details of medication, Procedure date $\&$ last visit to the Physician

RADIOTHERAPY:

(If Yes, mention the details of Procedure date $\&$ last visit to the Physician

PREVIOUS SURGERIES:

(If Yes, mention the details of medication, Procedure date \& last visit to the Physician

ACQUIRED DISEASES:

- AIDS

- HEPATITIS - B \& C 
(If Yes, mention the details of medication, Procedure date $\&$ last visit to the Physician

Date of last physical exam:

Date of last ECG:

Signature

Are you pregnant: YES/ NO(If yes specify the trimester

Are you breast feeding: YES/ NO(If Yes, since how long

Have you been under the care of physician during last 2 years?

(If yes, why \& when

Have you undergone general anesthesia for an operation?

(If Yes,Operation details \&any anesthesia complications noted

Are you taking medicine of any kind: YES/NO

(If Yes, For what \& since how long

Do you smoke YES/NO (If yes, How long how many

Do you consume alcohol YES/NO (If yes,How long how much

Do you chew Tobacco/ Areca nutYES/NO (If yes,How long how much

Are you allergic to any drugs: YES / NO

Pencillin... YES/NO

Codeine...YES/NO

Local anesthetic...YES/NO

Aspirin....YES/NO

General anesthetic....YES/NO

Barbiturates....YES/NO

Any other allergies in specific

Do you wear dentures...YES/NO

Do you wear lenses...YES/NO 
Any other medicines....YES/NO

( If yes specify the medicine

PATIENT SIGNATURE $\backslash$ DATE

WITNESS SIGNATURE $\backslash$ DATE 


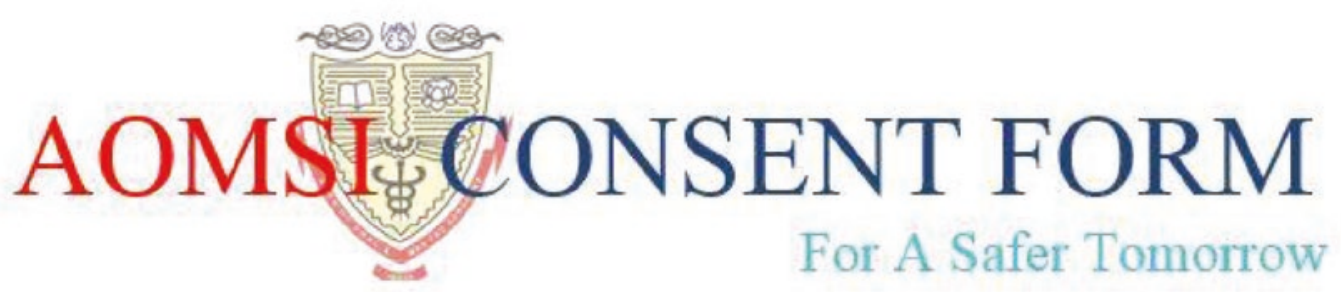

HEALTH QUESTIONNAIRE

Patient Name:

Date

Primary care Physician

Primary care dentist

Phone

Phone

Address

Address

Have you had any of the following ? Please check YES or NO

\section{Yes No}

Recurrent illness(Within one year)

Cough, cold, flu(Within 2 months)

Nose obstruction

Shortness of breath

Lung disease

Asthma

Bronchitis

Emphysema

Heart trouble

Chest pain

Heart attack

Irregular heart heat

Yes No

Heart murmur

Rheumatic fever

Scarlet fever

Arthritis

Artificial joints

Cortisone 
High blood pressure

Pacemaker

Heart Surgery

Excessive bleeding

Anemia

Treatment of Tumor

Yes No

seizures/ epilepsy

psychiatric disorder

liver disease

stroke

hepatitis

Stomach ulcer

Diabetes

Kidney disease

HIV

AIDS

Others serious illness

Date of last physical exam Date of last ECG

Yes___ No___ Are you pregnant?

Yes__ No___ Have you been under the care of physician during the last two years?

Yes___ No___ Have you been made unconscious for an operation?

List anesthesia complications

Yes___ No___ Are you taking medicine of any kind? List

Yes___ No___ Do you smoke?___ How long?____ How much?

Are you allergic to any drugs : if Yes

Yes___ No___ Pencillin.Yes__ No___ Codeine

Yes___ No___ Novocain Local Anesthetic.Yes___ No___Aspirin

Yes__ No___ General Anesthetics_ Yes__ No___ Barbiturates

Yes__ No___ Do you wear dentures?

Yes__ No___ Do you wear contact lenses

Yes__ No___ Other medicines. 
Signature of persons completing this form

$\begin{array}{lll}\text { Age Weight___ } & \text { BP } & \\ \text { Reviewed by } & - & \text { Date Reviewed }\end{array}$




\section{Consent for Minor oral surgery}

\section{AOMSI CONSENT FORM \\ For A Safer Tomorrow}

\section{CONSENT FOR MINOR ORAL \&MAXILLOFACIAL SURGERY}

PATIENT'S NAME

DATE

PLACE

DIAGNOSIS

TREATMENT PLAN

- My doctor has explained to me that there are certain inherent and potential risks and side effects associated with my proposed treatment and in this specific instance they include, but are not limited to :

1. Post-operative swelling and discomfort that may require several days of recovery.

2. Prolonged or heavy bleeding that may require additional treatment.

3. Injury or loosening of adjacent teeth or fillings.

4. Post-operative infection that may require additional treatment.

5. Stretching of the corners of the mouth that may cause cracking or bruising and may heal slowly.

6. Restricted mouth opening during healing sometimes related to swelling and muscle soreness and sometimes related to stress on the jaw joints(TMJ),especially when TMJ problem already exists.

7. A decision to leave a small piece of root in the jaw when its removal would require extensive surgery or risk of other complications.

8. Fracture of the jaw (usually only in more complicated extraction or surgery)

9. Injury to the nerve adjacent to teeth, resulting in pain numbness tingling or sensory disturbances on the chin, lip, cheek, gums or tongue and which may persist for several weeks, months, or in rare instances permanently.

10. It has been explained that during the course of treatment unforeseen conditions may result that may require change in the procedure, I authorize my Doctor to use professional judgement to perform such additional procedures that are necessary to complete my surgery. 
The Anaesthetic I have chosen for my surgery is

$\square \quad$ Local anaesthesia

$\square \quad$ Local with oral premedication

$\square \quad$ Local with intravenous sedation

$\square \quad$ General anaesthesia

It has been explained to me and I fully understand that a perfect result is not or cannot be guaranteed.

I have read and fully understood the above and discussed this operation and alternative treatment with . He has given me ample opportunity to ask questions about specific points and has answered those questions to my satisfaction.

PLEASE ASK YOUR DOCTOR IF U HAVE QUESTIONS CONCERNING THIS CONSENT FORM 


\section{Consent for Implant}

\section{AOMSI:CONSENT FORM For A Safer Tomorrow \\ ORAL \& MAXILLOFACIAL SURGERY CONSENT FOR DENTAL IMPLANT SURGERY}

Patients Name Age/Sex

Date

\section{Please initial on each page after reading. If you have any questions, please ask your doctor BEFORE initialing.}

1. I hereby authorize Dr. and assistants to treat the condition described as

2. The procedure offered to treat the condition has been explained to me and I understand the nature of the procedure to be:

3. I understand that incisions will be made in my mouth for the purpose of placing one or more endosteal root form structures (implants) in my jaw to serve as anchors for a missing tooth or teeth replacement or to stabilize a crown (cap), bridge, or denture. I acknowledge that the doctor has explained to me the procedure, including the number and location of the incisions and the type of implant to be used. I understand that the crown, bridge or denture that will be attached to this implant(s) will be made and attached by Dr. and that a separate charge will be made by the office.

4. I understand that the implant(s) may need to remain covered by gum tissue for at least three months before being used and that a second surgical procedure may be needed to uncover the top of the implant. No guarantee can be or has been given that the implant(s) will last for a specific time period. It has been explained to me that once the implant is inserted, the entire treatment plan must be followed and completed on schedule.If the planned schedule is not carried out, the implant(s) may fail.

5. I have been informed of possible alternative methods of treatment (if any), including

I understand that other forms of treatment or no treatment at all are choices that I have and the risks of those choices have been presented to me.

6. My doctor has explained to me that there are certain inherent and potential risks and side effects of any surgical procedure and in this specific instance such risks include but are not limited to: 
A. Post-operative discomfort, Pain and swelling that may require several days of at- home recuperation.

B. Prolonged or heavy bleeding that may require additional treatment.

C. Injury or damage to adjacent teeth and soft tissue.

\section{Signature}

D. Post-Operative infection and inflammation of soft tissues around the implant that may require additional treatment.

E. Stretching of the corners of the mouth that may cause cracking and bruising and may heal slowly.

F. Restricted mouth opening for several days; sometimes related to swelling and muscle soreness and sometimes related to stress on the jaw joints (TMJ).

G. Injury to nerve branches in the lower jaw resulting in numbness, pain or tingling of the chin, lips, cheek, gums or tongue on the operated side(s). These symptoms may persist for several weeks, months or, in rare instances may be permanent.

$\mathrm{H}$. Opening into the sinus (a normal bony chamber above the upper back teeth) requiring additional treatment. If the sinus is intentionally entered (sinus-lift procedure with grafting), there may be several weeks of sinusitis symptoms requiring certain medications and additional recovery time.

I. Fracture of the jaw or perforation of thin bony plates.

J. use of other materials which may have to be removed at a later date:

$\mathrm{K}$. Bone loss around implants and loosening of implants.

L. implant or prosthesis fracture, or loss of the implant due to rejection by the body.

M. Allergic or adverse reactions to any medications.

N. Accidental swallowing of foreign material.

O.other

7. It has been explained to me that during the course of surgery unforeseen conditions may be revealed which will necessitate extension of the original procedure or a different procedure from that set forth in paragraph 2 above. I authorize my doctor and his staff to perform such additional procedures as are necessary and desirable in the exercise of professional judgment.

8. I understand smoking is extremely detrimental to the success of my implant surgery. I agree to cease all forms of use of tobacco for 2-3 weeks after surgery, including the later uncovering procedure (when necessary), and to make a strong efforts to give up smoking entirely.

9. I consent to the administration of anesthesia I have chosen, which is:

$\triangle$ Local

QLocal with Nitrous Oxide / Oxygen Analgesia

$\triangle$ Local with oral Premedication

$\nabla$ Local with Intravenous Sedation

$\nabla$ General Anesthesia

10.ANESTHETIC RISKS include: discomfort, swelling, bruising, infection, prolonged numbness and allergic reactions. There may be inflammation at the site of an intravenous injection (phlebitis which may cause prolonged discomfort and / or disability, and may 
require special care. Nausea and vomiting, although are rare, may be unfortunate side effects of IV anesthesia. Intravenous anesthesia is a serious medical procedure and, although considered safe, carries with it the risk of heart irregularities, heart attack, stroke, brain damage or death.

\section{Signature}

\section{YOUR OBLIGATIONS IF IV ANESTHESIA IS USED}

A. Because anesthetic medications cause prolonged drowsiness, you MUST be accompanied by a responsible adult to drive you home and stay with you until you are recovered sufficiently to care for yourself. This may be up to 24 hours.

B. During recovery time ( 24 hours) you should not drive, operate complicated machinery or devices or make important decisions such as signing documents, etc.

C. you must have a completely empty stomach. It is vital that you have nothing to eat or drink for eight (8) hours prior to your anesthetic. To do otherwise may be life-threatening. D. However, it is important that you take any regular medications (high blood pressure, antibiotics, etc.) Or any other medications provided by this office, using only a small sip of water.

11. I understand that no guarantee can be promised and I give free and voluntary consent for treatment.

My signature below signifies that all questions have been answered to my satisfaction regarding this consent and I fully understand the risks involved of the proposed surgery and anesthesia. I certify that I speak, read, and write English.

\section{BEFORE SIGNING, PLEASE ASK YOUR DOCTOR IF YOU HAVE ANY QUESTIONS CONCERNING THIS CONSENT FORM.}

\section{Patient's (or Guardian's) Signature \&Date}

\section{WitnessSignature}

1)

2)

\section{Doctor`s Signature}




\section{Consent for Orthognathic surgery}

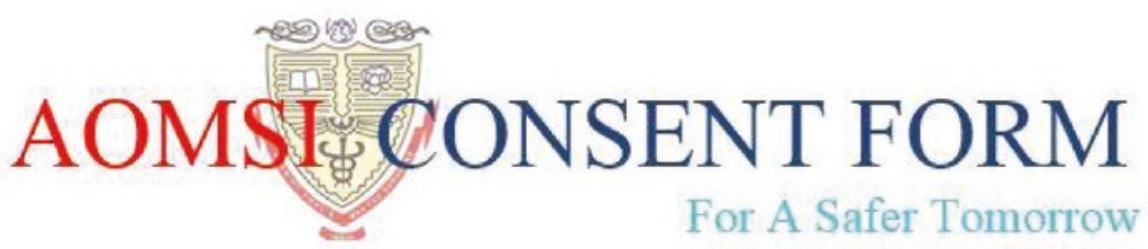

\section{ORAL AND MAXILLOFACIAL SURGERY CONSENT FOR ORTHOGNATHIC SURGERY}

Age /sex

Date

Please initial on each page after reading. If you have any questions, please ask your doctor BEFORE initialing.

Orthognathic surgery is being planned for you, and it is important that you understand the benefits and risks of such surgery. This is NOT minor surgery and you have the right to be fully informed about your condition and the recommended treatment plan. The disclosures in this consent are not meant to alarm you, but rather to provide information you need in order to give or withhold your consent to the planned surgery.

1. I hereby authorize Dr. and staff to treat the condition described as:

2. The surgical procedure planned to treat the above condition has been explained to me and I understand the nature of the treatment to be:

3. I have been informed of possible alternative forms of treatment (if any), including:

4. My doctor has explained to me that there are certain potential risks and side effects of the surgery planned, some of which may be serious. They include, but are not limited to:

A. Facial and jaw swelling after surgery, usually lasting several days.

B. Bleeding, both during and after surgery, which may sometimes be severe enough to require blood transfusion. I have been informed about the opportunity for blood donation before surgery so that, my own blood may be transfused back to me (auto transfusion) if necessary.

C. Allergic reaction to any of the medications given during or after surgery.

D. Delayed healing of the bony segments; rarely requiring a second surgery and/or bone graft to repair. 
E. Relapse: the tendency for the repositioned bone segments to return to their original position, which may require additional treatment, including surgery and/or bone grafting.

F. Bruising and discoloration of the skin around the jaws, eyes and nose. Possible Hematoma at injection site .

G. Diminished sense of smell (anosmia) in the upper jaw surgery.

H. A change in cosmetic appearance. Although this is primarily a procedure to restore jaw function, I am aware of some expected change in my appearance. I understand that certain cosmetic changes may not be totally predictable. There may also be changes in speech patterns which may require additional treatment.

I. Loss of feeling, pain or a tingling numbness in my chin, lips, tongue, gums, or teeth which occurs in a significant number of patients. Loss of taste sensation in tongue and palate. These symptoms may last for several days, weeks or months. I have been told that there is some chance that it may be permanent.

J. Possible decreased function of muscles of facial expression.

K. Scarring from external skin incisions if certain rigid fixation methods are used.

L. Malfunctioning or breakage of hard ware. Possible need for additional procedures to remove fixation devices, pins, screws, plates or splints.

M. In certain cases where bone cuts may be made in the marrow space between teeth, there is the possibility of devitalization of those teeth which may require later root canal procedures, and may result in the loss of these teeth.

$\mathrm{N}$ Fracture of the maxilla and mandible due to improper mobilization or incomplete osteotomies

O. In upper jaw surgery, the sinus will be affected for several weeks, and there may bleeding from nose in postoperative period. There may be a need for further sinus surgery to remedy any lingering problems.

P. Post-operative infection which may cause loss of adjacent bone and/or teeth and which may require additional treatment for a prolonged period of time.

Q Change in position of the jaw joints (TMJ) which may cause post-operative discomfort, bite change and chewing difficulties. If TMJ symptoms existed before surgery, there may be no improvement and even some worsening of these symptoms after surgery.

R. Stretching of the corners of the mouth with resulting discomfort and slow healing.

S. Inflammation of veins (phlebitis) that are used for IV fluids and medications, sometimes resulting in pain, swelling, discoloration and restriction of arm or hand movement for some time after surgery.

T. Hypernasality of voice due to swelling of nasal mucosa in immediate post operative period. Diffculty in swallowing and speech in cases of cleft patients due to velopharyngeal incompetence. 
U I consent to being photographed (head and neck region only) before and After surgery and during the operation to be performed.

These photographs may be used for medical, scientific or educational purposes, provided my name is not revealed by the pictures

V Airway compromise and fall back of tongue in cases of set back surgeries of mandible.

5. General anesthesia will be used for this surgery and I have been told of the risks, including bronchitis, pneumonia, hoarseness or voice changes, cardiac irregularities, heart attack or death. I am aware of the importance of not having anything by mouth (including clear liquids unless specifically authorized by my doctor or anesthesiologist) FOR EIGHT (8) HOURS PRIOR TO AND (8) HOURS AFTER SURGERY. TO DO OTHERWISE MAY BE LIFETHREATENING!

6. I realize the importance of providing true and accurate information about my health, especially concerning possible pregnancy, allergies, medications and history of drug or alcohol use. If I misinform my doctor I understand the consequences may be lifethreatening or otherwise adversely affect the results of my surgery.

\section{ABOUT WIRING OF TEETH}

If my teeth are wired together after this surgery, I understand there are certain associated risks and complications: oral hygiene will be diminished, there may be resulting gum disease, my teeth will feel slightly loose for some time after the wiring, compromised nutrition and there is always some concern about airway obstruction. I agree to carry wire cutters with me at all times when my jaws are wired and to avoid the use of alcohol and other activities that may cause nausea or airway problems.

Signature

\section{INFORMATION FOR FEMALE PATIENTS}

I have informed my doctor about my use of birth control pills. I have been advised that certain antibiotics and other medications may neutralize the preventive effect of birth control pills, allowing for conception and pregnancy. I agree to consult with my personal physician to initiate additional forms of birth control during the period of my treatment, and to continue those methods until advised by my personal physician that I can return to the use of oral birth control pills. 
By signing this consent form, I acknowledge that I have read it completely and understand the procedure to be performed, the risks, and the alternatives to surgery. I have had all my questions answered to my satisfaction. I was under no pressure to sign this form and have made a voluntary choice to proceed with surgery. The fee for services has been explained to me and is satisfactory and I understand there is no warranty or guarantee as to the result and/or cure and that my condition may return or become worse. I certify that I speak, read and write English.

\section{Patients (or guardian`s) signature \& Date}

\section{Witness signature:}

1.

2.

Doctor`s signature 


\section{AOMSI: CONSENT FORM \\ For A Safer Tomorrow}

ORAL AND MAXILLOFACIAL SURGERY

CONSENT FOR TREATMENT FOR REPAIR OF TEMPORO-MANDIBULAR JOINT

Patient's Name

Age/Sex

Date

Please initial on each page after reading. If you have any questions, please ask your doctor BEFORE initialing.

Dr. has explained to me about the pathology (disease) that exists in my right and/or left temporomandibular joints (lower jaw joint).

I understand that my condition of limited or compromised function and/or pain may be secondary to a number of possible processes including, but not limited to

1.Traumatic injury

Mark the symptoms

2. Malocclusion

3. Articular displacement (cartilage dislocation)

4. Degenerative joint disease, inflammation

5. Infection

6. Arthritis

7. Vascular injuries( hematoma formation) 
8. Instrument breakage during arthroscopy

9. Ankylosis( fibrous union / bony union of joint)

10. Chronic pain

11. Material failure ( foreign body reaction)

12. Frey`s syndrome (sweating over temporal region on operated side)

13. Neruosensory disturbances (numbness over skin and adjacent area of operated site)

14. Otology complications ( ear related)

15. Intracranial injuries ( Dural tear, cerebrospinal fluid leak)

16. Post operative maxilla-mandibular fixation

17. Objectionable scar formation.

18 Facial swelling lasting for longer period of time

I understand that the surgery to be performed is an exploratory procedure and the treatment rendered at that time will be based on the findings during surgery.

Surgical treatment may includes mark the procedure

1. Meniscus repair

2. Meniscectomy (removal of cartilage)

3. Placement of an implant 


\section{Eminectomy}

5. Condylectomy.

6. Arthroscopy

7. Arthrocentisis

8. Gap arthroplasty( release of ankylotic mass)

9.Ligament Plication

10.Interpositional Arthroplasty

11.TMJ Reconstruction

I (we) understand that my surgeon may discover other or different conditions which require additional or different procedures than those planned.

I (we) understand that no warranty or guarantee has been made to me as to a result or cure. I (we) also realize that the following risks and hazards may occur in connection with this particular procedure:

1. Facial nerve paralysis with inability to close eyelid on the affected side.

2. Inability to wrinkle the forehead.

3. Inability to blow air from mouth

4. burning sensation of eye due to inability to close eyelids

5. drooling of saliva from corner of mouth

6. Infection. 
7. Resultant malocclusion (incorrect bite) and limited opening of jaw.

8. Lack of improvement or worsening of pain and jaw dysfunction.

9. Further degenerative changes with the temporomandibular joint (TMJ).

Patients (or guardian`s) signature \& Date

Witness signature:

1.

2.

Doctor`s signature 


\title{
7. Consent for Trauma
}

\section{AOMSI CONSENT FORM \\ For A Safer Tomorrow}

\section{ORAL \&MAXILLOFACIAL SURGERY}

CONSENT FOR TREATMENT FOR REPAIR OF FACIALBONE FRACTURES

\author{
Patient's Name \\ Age/Sex \\ Date
}

Please initial on each page after reading. If you have any questions, please ask your doctor BEFORE initialing.

My doctor has explained to me that there are inherent and potential risk and side effects associated with my proposed treatment and in this specific instance, but they are not limited to

1. Damage to or loss of teeth in the area of trauma or fracture, loss of vitality of those teeth with requirement for future root canal therapy, loss of dental restoration, accidental swallowing or aspiration of tooth or foreign object, devitalization of bone and soft tissue in the area of trauma which may result in some loss of tissue.

2. Unusual procedures required during surgery such as incomplete removal of tooth, which endanger adjacent vital structures.

3. Post operative swelling, discomfort, bruising, bleeding, hematoma (blood clot), wound infection or dehiscence, sinusitis and limitations of function, any of which require further care.

4. Adverse or allergic reactions to medications or anesthesia causing multiple side effects, some of which may be serious and require additional care or hospitalization.

5. Reaction to foreign material which may have been introduced into the wound by the trauma, or "tattooing" of the skin or mucosa from particles of foreign material

6. Change in occlusion (bite) and jaw function after treatment; secondary problems of the jaw joint (TMJ) which may be prolonged, or even permanent, and which may require future treatment.

7. Possibility of otologic (ear related) complications such as perforation, infections, decrease in function of parotid gland( one of the gland responsible for saliva secretion), formation of fistula over preauricular\& retromandibular region(areas of lateral 
surface of face), mandibular hypomobility in long term experience, ankylosis of TMJ during surgeries of TMJ joint.

8. Scarring either inside or outside of the mouth, depending on the nature and force of the trauma and the locations of certain incisions required in treatment.

9. Facial muscle weakness particularly of the lip, eyelid or other muscles of expression caused by injury to motor nerves in the area of the trauma. Such weakness may be partial or total and may be temporary or permanent.

10. Sensory nerve injury causing pain, numbness, or other sensory alterations anywhere in the mouth, tongue, cheek, lip, and areas of facial skin which may be temporary or permanent.

11.Wiring the teeth together during the time required for healing of bone fractures will significantly reduce oral hygiene effectiveness, which may then lead to or worsen periodontal (gum) disease, bleeding gums, discomfort and loosening of teeth. Following treatment for facial injury, any such conditions must be treated. Jaw wiring will decrease normal diet and cause temporary weight loss.

12. Certain wires, screws, plates, splints or other fixation devices may be introduced, and some may require later removal.

13. Unusual effects related to hardware used such as metal sensitivity, Infection, screw fracture, plate fracture or plate exposure.

14. Non-union or malunion of bony fractures, possibly requiring re-treatment. Some cosmetic or functional deformity may occur in areas adjacent to the trauma or repair

I understand that additional injury may be discovered during treatment that might necessitate a change in approach or a different procedure from those explained above and I authorize my doctor to perform such procedures that are necessary and advisable in the exercise of professional judgment.

I understand that this is complex treatment and there can be no guarantee of complete resolution of my present symptoms or jaw/teeth/facial bone injury. Occasionally there may be increased symptoms post-operatively (for example, numbness). I also understand that additional treatment may be necessary post-operatively, including (but not restricted to) physical therapy, reconstructive dentistry, orthodontics, retreatment of bone fractures including bone grafting, removal of certain fixation devices, or TMJ treatment. I agree to cooperate with my doctor's recommendations during treatment, realizing that lack of cooperation will result in a less-than-optimal result.

I have discussed my past medical history with my doctor and have disclosed all diseases and medications, including alcohol and drug use (past and present). 
Signature

I have had an opportunity to have all my questions answered by my doctor that all blanks on this form were filled in prior to my signing, and I certify that I understand English. My signature below signifies that I understand the surgery and anesthetic that is proposed for me, together with the known risks and complications associated. I hereby give my consent for such surgery and anesthesia I have chosen.

\section{Patients(or guardian`s) signature \&Date}

\section{Witness signature:}

1.

2.

Doctor`s signature 


\section{AOMSI CONSENT FORM For A Safer Tomorrow}

Here is the Consent for informed consent and illiterates. This as per the standard requirement. You can dilute it or modify it.

1. All consent forms should be in the language of the majority of the population. Therefore it must be in the Vernacular of that region plus English or any other popular language. The English Consent form should be translated to the local language. There are two ways of doing it so that the essence and meaning are not lost.

A. Ethical committee approved consent forms in order to remain valid will need ' back translation'. The suggested or approved consent form must be translated into the vernacular. The thus translated matter must then be translated back to the original English by another person. Then the original and the 'back translated versions are compared. If the meaning remains unchanged then the translation is accepted. Please note that this is required only in approved consent forms in research etc. In the clinical setting the AOMSI consent for is only a template and such rigorous measures may not be necessary.

B. Alternately the approved consent in English can be translated by a Government approved translator ( usually a University translation department). E.g. The Tamil University in Tanjore does approved translations.

2. For obtaining Informed Consent of illiterate persons the Consent form can be read out to the person giving consent in the language he/ she understands in the presence of an independent third party or relative of patient who should be literate. The consent form is then signed and attested by the independent witness in addition to signature or thumb impression of the consenting person.

3. In case of children below 18 years, the parent or legal guardian can sign on behalf of the children. However, child rights activists and the new law in several countries may require a consent (particularly in older children who can comprehend issues). Technically, in India, children below 18 are considered to be 'not legally competent'. 
4. In mentally retarded or persons incapable of consenting due to mental incapacity, the parent or legal guardian (if unavailable -institutional heads of organizations taking care of them can sign on their behalf).

5. In hearing impaired illiterates the consent must be explained by sign language or any means that is used for communication to translate the document. It needs third party attestation. Similarly, in visually impaired persons the consent can be obtained through Braille or by oral communication with third party attestation.

Today, in many countries video recorded informed consent procedures are utilised. It may become mandatory in India too.

Caveat: informed consent, however carefully taken can be challenged on the grounds of being an unequal contract influenced by fiduciary relationship in doctor- patient relationship.

The above is my personal opinions based on experience and the use of consent approved by Ethiconsult Services of which Dr George Paul was a member secretary. It can be modified as per personal perception of what constitutes adequate consent. 


\section{AOMSI CONSENT FORM For A Safer Tomorrow}

\section{Informed refusal of treatment.}

This form is primarily used when any recommended treatment is refused by a patient. (It may also be used for patients with TMJ implants who remain both asymptomatic and without imaging changes in joints and who, contrary to FDA and AAOMS guidelines, do NOT wish to have TMJ implants removed)

I have been informed by DRof my condition and the recommended treatment consisting of :

I have also been offered alternative treatment which include:

Afterconsideringthetreatment possibilities offered, and having the benefits and risks of each explained to my satisfaction, I have voluntary chosen to :-

I understand that my decision is contrary to my doctor's recommendation and that my condition may significantly worsen as a result, may require additional therapy additional therapy/ or hospitalization, and in rare circumstances may be life threatening. I AGREE TO RETURN TO THIS OFFICE FOR PERIODIC MONITORING OF MY CONDITION AS scheduled by my doctor. 
I realize that I may consider my decision at any time by notifying my doctor.

Patient 's(or Guardian) signature

Date

Witness's Signature

Date

Doctor's Signature

Date 


\section{A.2 Quantification of Disability}

\section{A.2.1 Quantification of Dento-facial Disability/ Deformity: A Proposal [19]}

Form and function are the quintessence of human life. Disability and deformity are interruptions to this harmony. Disability/deformity may be congenital or acquired. Governments have a social responsibility to mitigate such afflictions by creating an environment for re integrating them into normal social life. Most welfare states provide benefits for persons with disability.

Disability can also be caused by accidents, interpersonal violence and iatrogenic causes. These situations have legal overtones and often require compensation in some form. Benefits and compensation can only be calculated if the disability is quantified. Orthopedic disabilities in Civil and Military life have been calibrated and quantified. Similarly other disabilities involving loco motor, neurological, visual and hearing deficit have also been quantified. Unfortunately the maxillofacial region has not been adequately addressed in any of these quantification charts.

Quantification of the maxillofacial region is unique on account of the fact that there are two criteria to be evaluatedDisability and Deformity. While disability is more readily calculated, deformity is highly subjective and therefore any award for the latter is bound to be arbitrary. However it is not possible to ignore the importance of deformity to the face, and an attempt is made to establish a broad parameter in which it can be assessed.

\section{Review of Quantification Criteria}

Quantification of orthopedic disability is well established and has been in use for social benefits, rehabilitation, assistance and percentage reservations in labour market placement of disabled people. It has also been in use for legal and insurance compensations due to accidents, interpersonal violence and occupational diseases. The Phulhems profile by the Canadian Army was established as early as 1943. The McBrides criteria was the established reference in India till 1980. It did cover some aspects of the maxillofacial region and was generally accepted for dental injuries and dental loss. The McBrides criteria (1955) was replaced in India by the "Manual for Doctors to Evaluate Permanent Physical Impairment" (1981). Unfortunately the impairment and disability of the face is covered rather incomprehensively and inadequately, relegating the whole area of the face to one half of a chapter, with hardly 30 points being allocated to the face. Not one maxillofacial surgeon sat on the expert committee of 45 advisors. In the realm of physical rehabilitation and orthopedics, numerous references are available. Kessler (1970) covered various aspects of upper and lower extremity disabilities. The American Academy of Orthopedic Surgeons Manual (1966) discusses the concept of permanent impair- ment through a series of questions that reveal the permanency of the deficit. The Govt. of India notification (1986) covers visual disabilities, locomotor disabilities and hearing and speech disabilities. It recommends that Kessler's formula can be taken as a general guideline.

Significantly the only other Indian guideline for Maxillofacial region comes through a Government of Tamilnadu notification (1974) where complete facial disfigurement is dealt with. It simply awards a $50 \%$ for total facial disfigurement. No break up figures is given for type or severity of disfigurement.

The American Association of Oral and maxillofacial Surgeons and American Medical Association have given guidelines for assessment of maxillofacial injuries and disabilities. They however need modification to suit our population and needs.

The authors have depended on two major sources while making this evaluation.

1. Objective Evaluation of Impairment and Ability in Locomotor Handicapped by Sabapathyvinayagam Ramar. An excellent reference book on Physical Medicine and Rehabilitation.

2. Guidelines to the Evaluation of Impairment of The Oral and Maxillofacial Region-issued by the American Association of Oral and Maxillofacial Region.

The authors have modified the guidelines of the above sources to arrive at the recommendations.

The general aim of the exercise was to evolve quantification criteria for disabilities and deformities of the Maxillofacial region taking into account the special features of the problems encountered in India. It also endeavours to simplify the percentages awarded by eliminating complex variables. The evaluation adopts a position of awarding a $100 \%$ to the face to be divided between deformity $(50 \%)$ and disability $(50 \%)$. It does not try to evaluate facial impairment as a part of the total body as it would significantly reduce the quantum of impairment and thus defeat the purpose of this exercise. Consider a situation where $100 \%$ has to be divided between cardiovascular, alimentary, central nervous and locomotor systems in addition to sexual dysfunction, liver dysfunction, renal, endocrine and metabolic dysfunctions. Further distribution amongst visual, hearing, etc. will certainly minimize any help of giving value to the face.

The evaluation has also eliminated the need to go into variables like age, sex and occupation, which will modify the award percentages. These will rest within the realm of the government agencies, judiciary or insurance agents.

The criteria formulated shall simply make a statement of disability/deformity based on standards established within the purview of the $100 \%$ for the face-equally divided 
amongst the various structures and functions. The total of these shall remain within hundred utilizing the formula

$$
A+\frac{B(100-\mathbf{A})}{100}
$$

where, $\mathrm{A}=$ higher value and

$B=$ lower value.

Definitions

Based on Govt. of India Gazette Part I section 1 No. 4-2/83HW III Ministry of Welfare, 1986.8

- Impairment: is defined as any loss (or) abnormality of psychological, physiological (or) anatomical structure (or) function.

- Disability: WHO defines disability in the context of health experience as any restriction or lack (resulting from an impairment) of ability to perform an activity in the manner (or) within the range considered normal for a human being.

- Deformity: facial disfigurement involving soft and hard tissues arising from multiple genetic factors, environment influences, acquired defects, neoplastic processes and trauma.

Recommended Quantification for the Dento-facial Region Areas of Deformity Evaluation-Hard Tissues:

\section{A. Loss of Teeth:}

$\begin{array}{ll}\text { Anteriors } & \text { Deformity/Disability } \\ \text { All anteriors (upper and lower) } & : 25 \% \\ \text { Between } 8 \text { and } 11 & : 20 \% \\ \text { Between } 4 \text { and } 7 & : 15 \% \\ \text { Between } 2 \text { and } 3 & : 10 \% \\ \text { One tooth } & : 05 \%\end{array}$

Though these are disabilities and deformities that can be replaced, it deserves the above percentile as the strength and function of false teeth are not considered equal to natural teeth. Orthopedic deformities are evaluated even if prosthesis is given.

Posteriors Disability

- Excluding third molars and including premolars.

$\begin{array}{ll}\text { All posteriors (16) } & : 25 \% \\ \text { Between 10 and 14 } & : 20 \% \\ \text { Between } 6 \text { and } 9 & : 15 \% \\ \text { Between 2 and } 5 & : 10 \% \\ \text { Occlusal discrepancy } & : 10-20 \% \\ \text { One tooth } & : 05 \%\end{array}$

Loss of teeth due to progressive dental pathology (e.g. Periodontitis, caries) are not considered. The dental surgeon will have to make an assessment based on the condition of remaining teeth or preexisting records.

\section{B. Loss of Bone (Disability/Deformity)}

Significant loss of bone causing

Deformity/Disability : : 10-25\%

Small bony fragment $: 5 \%$

C. Mal-united Facial Bones: (Depending on extent of Disability/Deformity)

Malunited facial bones $\quad 10-20 \%$

- Occlusion to be combined whenever affected.

This is an incomplete quantification and will have to be assessed by the surgeon on the basis of the degree of disability/deformity caused by the malunion.

\section{Orbital Deformity (excluding visual field assessment)}

Subjective evaluation based on:

Bony orbit : : 5-10\%

Soft tissue e.g.) etropian, scar etc : : 5-10\%

Composite deformities including

Telecanthus etc : $15-25 \%$

Areas of Deformity Evaluation-Soft Tissue

A. Soft Tissue-Non-reversible

Single linear scar : :5\%

Multiple or deforming scars

Including Keloids : : 10-30\%

Significant loss of soft tissue

E.g. Loss of nose, ear, lips etc : : 20-50\%

B. Facial Sensory Impairment (Ramar)

Face has 34\% sensory innervations of whole body.

Ophthalmic : $8 \%$

Maxillary : $8 \%$

Mandibular : $8 \%$

Tongue : $10 \%$

C. Impairment Rate for Mouth Opening (Ramar)

Impairment rate for interincisor distance of $4 \mathrm{~cm} \mathrm{:}: 0 \%$

Impairment rate for interincisor distance of $3 \mathrm{~cm} \mathrm{:} 10 \%$

Impairment rate for interincisor distance of $2 \mathrm{~cm}: 20 \%$

Impairment rate for interincisor distance of $1 \mathrm{~cm} \mathrm{:} 30 \%$

Impairment rate for interincisor distance of $0 \mathrm{~cm}: 50 \%$

D. Motor Disability (RAMAR)

Jaw muscles (masticatory) : :5\% right side, $5 \%$ left side

Tongue muscles $\quad: 15 \%$ either side.

E. Facial Nerve Impairment

Single branch : $05 \%$

Five branches : $25 \%$

Zygomaticotemporal : $10 \%$

Bilateral problems are not addressed.

F. Disfigurement criteria (AAOMS and AMA guidelines 1997 and 2002) 
- Class 1- $(0-5 \%)$ Disorder of cutaneous structure e.g. visible scars

- Class 2-(5-10\%) Loss of supporting structure with or without cutaneous disorder e.g. Depressed cheek and nose.

- Class 3-(10-15\%) Absence of normal anatomical area of face. E.g. Loss of eye or part of nose. Visual or hearing loss will have to be separately evaluated.

- Class 4-(15-35\%) Impairment of whole person. Facial disfigurement is so severe that it precludes social acceptance.

This criteria appears logical and it significantly simplifies an otherwise complex quantification of facial disfigurement. However we would encourage its use with the other mentioned parameters. The multiple percentages can be resolved with the Kessler's formula.

In multiple disabilities and deformities or when there is a combination of the two the Kessler's Formula $\mathrm{A}+\frac{\mathrm{B}(100-\mathrm{A})}{100}$ can be used, where $\mathrm{A}=$ the higher and $\mathrm{B}=$ lower value

Another formula has also been used by Ramar as per the Government of India notification: $\mathrm{A}+\frac{\mathrm{B}(90-\mathrm{A})}{90}$ again $\mathrm{A}$ being the higher value and $\mathrm{B}$ being the lower value.

The formula can be used in a few mock situations.

1. $\mathrm{X}$ has an injury resulting in the fracture of the mandible and loss of four incisors. He also develops a pareisis of the marginal mandibular nerve following surgery. His total percentile may be calculated thus: $\mathrm{A}=15 \%$ and $\mathrm{B}=$ $5 \%$.

$15+\frac{5(100-15)}{100}=19.25$, whereas the sum of both would have been $20 \%$.

2. $\mathrm{Y}$ has an injury resulting in the fracture of both condyles causing subsequent total bony ankylosis. He also has a large scar with keloid on his right cheek. His percentage is calculated thus:

$50+\frac{20(100-50)}{100}=60$ whereas the sum of two injuries would have been 70 . Please note that the value adjusts itself as the percentiles go up.

\section{Discussion}

Quantifying all kinds of disabilities/deformities is an enormous task. This paper attempts to deal with only those disabilities resulting from accidents. Congenital disabilities/ deformities such as those found in cleft-craniofacial anomalies will require a more extensive analysis. Similarly disabilities and deformities caused by aggressive tumours and cancers of the head and neck comprise a wide range of problems, which are not necessarily regional. Cancer in particular may have numerous associated problems ranging from donor site morbidity to psychological impact affecting quality of life and mental depression.

Dental injuries and their resultant disability/deformity are closely linked to aesthetics and mastication. For the purpose of awarding percentiles, the anterior teeth were considered for aesthetics and the posterior teeth for masticatory function. The awards are arbitrary and based on the relative dysfunction caused by the absence of teeth in the masticatory apparatus. The American Association of Oral and Maxillofacial Surgery (AAOMS) guidelines award percentages for the complete masticatory apparatus. It awards $24 \%$ for a person who is restricted to liquid diet (40-60\% if tube feeding is necessary) and $5-19 \%$ if person is restricted to semisolids (includes those with ability to wear dentures). We have taken the liberty of awarding points for individual teeth. However if the whole masticatory apparatus is to be evaluated, one may separately evaluate absence of teeth, occlusal disharmony, TMJ movement (craniomandibular articulation), muscle power etc and arrive at a figure by using the Kessler's formula of $\mathrm{A}+\frac{\mathrm{B}(100-\mathrm{A})}{100}$.

This appears as a reasonable formula, which accounts for individual disabilities within the framework of the masticatory apparatus.

Further the AAOMS guidelines classifies the percentiles into two categories (1) Percentage of normal. (2) Percentage impairment of whole person. The dichotomy does not seem reasonable and is likely to cause further confusion. Finer details such as lateral excursion etc which, have been dealt with in the AAOMS guidelines have been ignored.

Similarly the concept of deformity and disfigurement has been dealt with differently in the AAOMS and the AMA guidelines. The matter of disfigurement is complicated by issues such as personality crisis and the impact of social acceptance. As suggested earlier this criteria can be incorporated into Kessler's formula, thus resolving the issue of multiple disabilities and deformities.

Finally the question of who can give a disability certificate. The Indian sources are silent in the matter of maxillofacial injuries. However the law in many American states clearly provides for the role of a Board qualified Oral Surgeon or maxillofacial Surgeon to issue disability certification for the maxillofacial region.

Contrary to general perception, it is not necessary that these criteria need to be made by statutory bodies. General usage can give legal legitimacy. It would of course be in the best interest of the Surgeon, patient and the public if these suggestions can be scrutinized, amended and enlarged to accommodate a larger spectrum of disabilities and deformities. 


\section{A.2.1.2 Duties of Witness}

Failure to appear in court without valid reasons after warrant has been issued can invite contempt of court.

Exaggeration or false statements given under oath is not only unethical, but can invite punishment under sec. 181, Sec. 193.

\section{References}

1. Bernhard Wolf Weinberger. Pierre Fauchard, Surgeon-dentist: a brief account of the beginning of modern dentistry, the first dental textbook, and professional life two hundred years ago. 1941.

2. Moore W. The knife man. Transworld; 2010. pp. 223-4. ISBN 9781409044628. Retrieved 8 Mar 2012.

3. https://www.dental.upenn.edu/admissions-academics/ graduate-dental-education-programs/oral-maxillofacialsurgery-residency-m-d/

4. http://dental.nyu.edu/academicprograms/advanced-education-programs/oms6.html

5. Martin-Granizo R. Double degree in oral and maxillofacial surgery - is it necessary? IJOMS. 2017;02:126.

6. Amin M, Ahmed B. Dental education in Pakistan: current trends and practice. J Coll Physicians Surg Pak. 2010;20(8):497-8.

7. Mawatha NK. Prospectus, MD oral and maxillofacial surgery and board certification. Postgraduate Institute of Medicine, University of Colombo. 2011.
8. Zheng J, Fang B, Zhang S, Yang C, Shen G, Qiu W, et al. Oral and maxillofacial surgery in China: past, present and future. Open J Stomatol. 2013;03:354-8.

9. Fiehn N-E. Perspectives on dental education in the Nordic Countries. J Dent Educ. 2002;66(12):1374-80.

10. EACMFS. White book. Russia. 1st ed. 2017. http://beta.jointogethergroup.com/Society/members/whitebook/export.asp?wb=31

11. Kumar S. Training programmes in oral and maxillofacial surgery across the globe - a mini review. J Maxillofac Oral Surg. 2017;16(3):269-76

12. Revised Dentists (Code of Ethics) Regulations - 2014, Part II, Section 3, Sub-sec (1) of the Gazette of India.

13. http://www.thefreedictionary.com/informed+consent

14. Faden RR, Beauchamp TL. A history and theory of informed consent. Oxford University Press; 1986. p. 28, 123.

15. Faden RR, Beauchamp TL. A history and theory of informed consent. Oxford University Press; 1986.

16. Gasparini G, Boniello R, Moro A, Di Nardo F, Pelo S. Orthognathic surgery: a new preoperative informed consent model. J Craniofac Surg. 2009;20(1):90-2.

17. Krishnan NR, Kasthuri AS. Informed Consent MFAJI. 2007;63:164-166.

18. http://www.surgery.org/press/news-release.php?iid=125

19. Paul G. Medical law for the dental surgeon. Jaypee Publishers; 2004. p. 30.

20. Bolam Vs Friern Hospital managing committee. (1957) 2 AIIER 118.

21. IMA v VP Shantha and Oths 111 (1995) CPJ (SC).

Open Access This chapter is licensed under the terms of the Creative Commons Attribution 4.0 International License (http://creativecommons. org/licenses/by/4.0/), which permits use, sharing, adaptation, distribution and reproduction in any medium or format, as long as you give appropriate credit to the original author(s) and the source, provide a link to the Creative Commons license and indicate if changes were made.

The images or other third party material in this chapter are included in the chapter's Creative Commons license, unless indicated otherwise in a credit line to the material. If material is not included in the chapter's Creative Commons license and your intended use is not permitted by statutory regulation or exceeds the permitted use, you will need to obtain permission directly from the copyright holder. 